\title{
The TSH receptor reveals itself
}

\author{
Terry Davies, Russell Marians, and Rauf Latif
}

Division of Endocrinology, Diabetes and Bone Diseases,

Mount Sinai School of Medicine, New York, New York, USA

Address correspondence to: T.F. Davies, Department of Medicine, Box 1055,

Mount Sinai School of Medicine, One Gustave L. Levy Place, New York, New York 10029-6574, USA.

Phone: (212) 241-6627; Fax: (212) 241-4218; E-mail: Terry.Davies@mssm.edu.

J. Clin. Invest. 110:161-164 (2002). doi:10.1172/JCI200216234.

The thyrotropin receptor (TSHR), one of the primary antigens in autoimmune thyroid disease, is a target of both antigen-specific $T$ cells and antibodies in patients with this condition (1). Autoantibodies to the TSHR (TSHR-Ab) act as thyroid stimulating factor (TSH) agonists in autoimmune hyperthyroidism (Robert Graves disease) but as TSH antagonists in autoimmune hypothyroidism (Hashimoto thyroiditis). The TSHR antigen is primarily expressed in the epithelial cells of the thyroid follicles, but TSHR mRNA and protein have been reported in a variety of cell types, some of which show evidence of receptor activity (Table 1).

The TSHR gene, cloned in 1989 (2-5), maps to human chromosome $14 \mathrm{q}$ and encodes a predicted seventransmembrane, $G$ protein-coupled glycoprotein. Although it is similar to the luteinizing hormone receptor and the follicle-stimulating hormone receptor, the TSHR is the largest of the glycoprotein hormone receptors, due primarily to 8 - and 50 -amino acid insertions in its ectodomain (residues $38-45$ and 317-367) (6). As predicted from its cDNA, the TSHR has an unglycosylated molecular weight of $84 \mathrm{kDa}$ but the glycosylated holoreceptor runs on SDS-PAGE with an apparent molecular weight of $95-100 \mathrm{kDa}$. There are six potential N-linked glycosylation sites on the TSHR, and it was recently shown that the TSHR is also palmitoylated (7). The minimal $5^{\prime}$ promoter region required to confer thyroid-specific expression and cAMP autoregulation extends from 220 to 39 bp upstream of the transcription start site, but there are multiple transcription start sites between -89 and -68 bp (8).

\section{TSHR signal transduction, regulation, and maturation}

The TSHR, long known to signal via cAMP (9), can induce both the phospholipase C (PLC) and the protein kinase A signal transduction systems. Intracellular $\mathrm{Ca}^{2+}$ and PLC regulate iodide efflux, $\mathrm{H}_{2} \mathrm{O}_{2}$ production, and thyroglobulin iodination, while adenylate cyclase and cAMP regulate iodide uptake and transcription of thyroglobulin $(\mathrm{Tg})$, thyroid peroxidase (TPO), and the sodium-iodide symporter $(10,11)$. Photoaffinity labeling of the TSHR with azido-GTP followed by immunoprecipitation suggests that all four $\mathrm{G} \alpha$ subtypes are involved (12), but only $G \alpha_{s}$ and $G \alpha_{q}$ have been shown to mediate TSHR signals.

TSHR levels are positively regulated by TSH in normal cells (13), secondary to prolongation of the mRNA halflife, while exposure to high concentrations of ligand causes the receptors to be downregulated (14). Posttranslational proteolysis clips the TSH receptor (TSHR) into two subunits (referred to as $\alpha$, or A, and $\beta$, or B) (15, 16), linked to each other by disulfide bonds. These $\alpha$ and $\beta$ subunits are formed by intramolecular cleavage, apparently at multiple sites, with removal of an intervening polypeptide segment of approximately 50 amino acids (amino acids 317-367) $(17,18)$. Disulfide bonds that link the two subunits are then reduced, presumably by protein disulfide isomerase leading to release of the $\alpha$ subunit from the membrane-bound receptor $(17,19)$. This phenomenon of releasing the $\alpha$ subunit is referred to as receptor shedding and explains the approximately $3: 1$ excess of $\beta$ subunits found in thyroid membrane preparations (20). These observations also explain the early data indicating that the long-acting thyroid stimulator (LATS) activity in Graves patients' sera, now attributed to activating TSHR-Ab's autoantibodies, can be absorbed using the supernatant from frozen and thawed thyroid tissues (21). Moreover, such ectodomain shedding may also account for the puzzling size diversity of TSHRs detected by Western blot (20). Crucially, shedding also leads to a structural change in the $\alpha$ subunit once it is released from the receptora change whose consequences are considered by Chazenbalk et al. in this issue of the JCI (22).

Table 1

Tissue distribution of the TSHR

\begin{tabular}{lcccc}
\hline Tissue & Gene expressed & mRNA & Protein $^{\mathrm{B}}$ & References \\
Lymphocytes & TSHR & + & + & $32-34$ \\
Thymus & TSHR, NIS, TPO, Tg & + & + & 35,36 \\
Pituitary & TSHR & + & + & 37,38 \\
Testis & TSHR & + & + & 39,40 \\
Kidney & TSHR, Tg & + & + & 41 \\
Brain & TSHR & + & NR & 42 \\
Adipose/Fibroblast & TSHR & + & + & $43-48$ \\
Heart & TSHR & + & + & 49,50 \\
Bone & TSHR & + & NR & 51,52
\end{tabular}

${ }^{A}$ RT-PCR/in situ hybridization. ${ }^{B}$ Immunohistochemistry/ligand binding assay. NIS, sodium-iodide symporter; NR, not reported. 


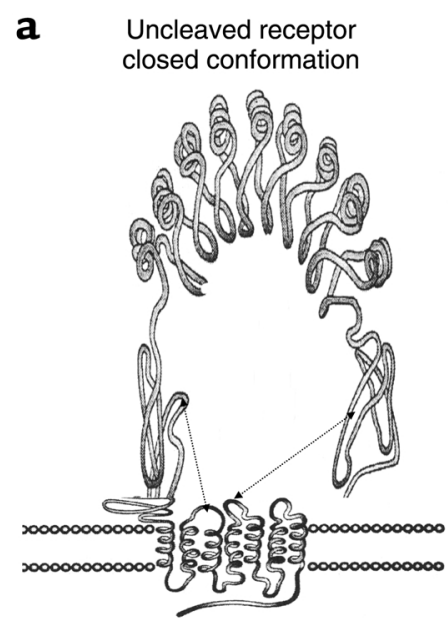

\section{Cleavage of TSHR and receptor} interactions with pathogenic antibodies Using modern techniques, Chazenbalk et al. (22) confirm the long-standing suspicion, raised by early work on LATSabsorbing activity, that the fractured TSHR has a higher affinity for TSHRAb's than does the intact, membranebound receptor. Using both secreted and glycosidylphosphatidyl inositolanchored (GPI) TSHR ectodomains, their elegant studies confirm that stimulating TSH receptor antibodies, which are directed primarily at the TSHR ectodomain, preferentially bind to these fragments rather than to intact membrane-bound receptor on the cell surface. This preferential binding distinguishes the agonistic TSHR-Ab's found in individuals with Graves disease from the blocking antibody type found in Hashimoto thyroiditis patients. These observations are also consistent with stimulating TSHR-Ab's being directed at a unique conformational epitope, which may be accessed more easily when the ectodomain is shed from the holoreceptor.

Apparently recognizing a conformational epitope on the receptor, activating TSHR-Ab's from susceptible individuals bind to the shed receptor ectodomain, on the so-called open form of the holoreceptor. Accumulating data from mutational analyses indicate that this receptor can shift from a "closed" (inactive) to an "open" (active) form, which can induce signaling when bound by TSH agonists, including activating autoantibodies. While TSHR cleavage and reduction are not necessary for signal transduction (23), interactions between the b Cleaved receptor

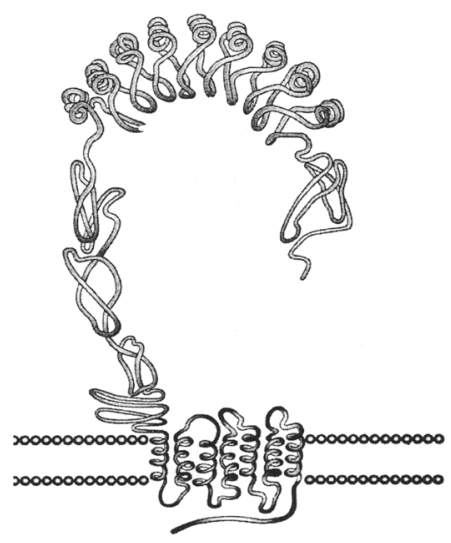
open conformation
Figure 1

Two possible structural configurations of TSH receptor. (a) The uncleaved receptor is shown with a "buried" structure. The ectodomain and transmembrane interactions result in a "closed" conformation (connecting dotted lines). (b) Cleavage may induce an "open" conformation, a step that is thought to be a precondition for subsequent changes in receptor localization and activity, as described in the text and shown in Figure 2. This figure is adapted from ref. 25 with permission. ectodomain and the extracellular loops of the transmembrane domains are critical for the maintenance of an inactive state (Figure 1; see also ref. 24). Consistent with this model, removal of the TSHR ectodomain yields a constitutively active receptor, suggesting that its presence inhibits an otherwise constitutively active $\beta$ subunit $(25,26)$. This model predicts that only the open form of the recep- tor should bind ligand and become activated. The observation (23) that a noncleavable TSHR mutant is able to signal could simply be explained by the mutated ectodomain forming an open structure.

Recent work from our laboratory has demonstrated that the TSH receptor is constitutively oligomeric (27). Using fluorescent resonance energy transfer between two different fluorescently

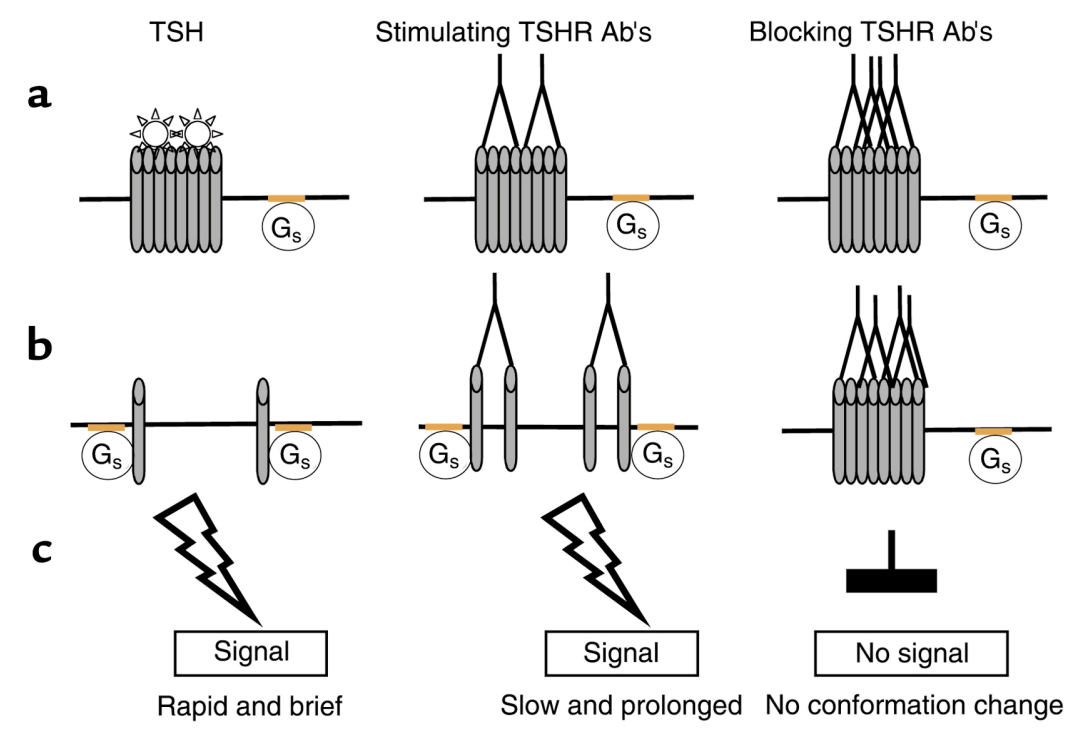

Figure 2

A model for oligomerization in TSH receptor signaling. (a) TSH receptors initially exist in an open conformation as cleaved oligomers residing on the cell surface outside lipid rafts. Signal-transducing $\mathrm{G}_{\mathrm{s}}$ proteins, on the other hand, are restricted to lipid rafts. (b) Following TSH binding, the oligomers break apart into monomers. Conversely, stimulating antibodies, as found in sera from patients with the autoimmune disorder Graves disease, are proposed to favor formation of TSH receptor dimers; blocking antibodies, are unable to bring about this conformational change. (c) Dissociated monomers, as well as dimers, move into the lipid rafts and bind to $\mathrm{G}_{\mathrm{s}}$ proteins, thereby initiating the signaling cascade. In the case of TSH, the signal is rapid and brief because of faster movement of monomers into the lipid rafts, in contrast to the retarded movement of the dimers. Multivalent blocking TSHR antibodies may cross-link the oligomers, thereby preventing them from dissociating and impeding their entry into lipid rafts. 
labeled TSHR constructs, we confirmed the presence of TSHR multimers in cell membranes, as we previously suggested based on molecular size (20). We have now also found that these oligomeric forms rapidly dissociate upon TSH binding (28) (Figure 2 ), indicating that ligand binding alters the shape of the receptor, promoting dissociation of the oligomeric receptors into active, open monomers. Moreover, murine monoclonal TSHR antibodies, which block TSH action, fail to mimic TSH or to promote TSHR monomer formation (R. Latif et al., unpublished data). If, as we suggest, the monomeric form of the TSHR can be recruited more efficiently into lipid rafts (29) than can the larger complexes, these observations may indicate a mechanism by which the monomer preferentially couples with $G$ proteins (30) to initiate signaling (Figure 2).

Although stimulating TSHR-Ab's are unique to patients with Graves disease, their serum has been shown to most commonly contain a mixture of both blocking and stimulating TSHR-Ab's (1), and the bioactivity of the serum reflects a balance between the two. Unfortunately, the surprising failure of many investigators to isolate high-affinity monoclonal stimulating TSHR antibodies represents a major impediment to understanding the basis of this response. Nevertheless, we hypothesize that stimulating, but not blocking, TSHR$A b$ 's lead to the formation of TSHR dimers, which may still be able to move into the lipid rafts and initiate signal transduction (Figure 2). While monomers can move quickly within the lipid rafts, as shown by fluorescence recovery after photobleaching experiments, movement of dimeric receptors within the rafts is predicted to be slower, perhaps accounting for the relatively weak but prolonged signaling that results from exposure to LATS sera (31).

The failure to obtain monoclonal stimulating antibodies of high affinity to the TSHR remains a great enigma in modern thyroid research. While blame has always been assigned to insensitive detection systems combined with a small repertoire of TSHR-Ab-secreting B cells, it is also possible that the state of the TSHR, not just the nature of the antibody, determines whether antibody binding can activate signaling. Combinations of TSHR-Ab's, which on their own may not activate the receptor, may be required to shift the receptor into an activated form - perhaps by promoting TSHR monomer formation. This hypothesis is eminently testable and promises more excitement in this rapidly developing field.

\section{Acknowledgments}

This work was supported in part by NIH grants DK-52464, DK-35764, and DK-45011 (to T. Davies), and the David Owen Segal Endowment (to R. Latif).

1. Davies, T.F. 2000. Werner \& Ingbar's the thyroid: a fundamental and clinical text. Lippincott Williams \& Wilkins. Philadelphia, Pennsylvania, USA. 518-530.

2. Parmentier, M., et al. 1989. Molecular cloning of the thyrotropin receptor. Science. 246:1620-1622.

3. Misrahi, M., et al. 1990. Cloning, sequencing and expression of human TSH receptor. Biochem. Biophys. Res. Commun. 166:394-403.

4. Nagayama, Y., Kaufman, K.D., Seto, P., and Rapoport, B. 1989. Molecular cloning, sequence and functional expression of the cDNA for the human thyrotropin receptor. Biochem. Biophys. Res. Commun. 165:1184-1190.

5. Gross, B., Misrahi, M., Sar, S., and Milgrom, E. 1991. Composite structure of the human thyrotropin receptor gene. Biochem. Biophys. Res. Commun. 177:679-687.

6. Rapoport, B., Chazenbalk, G.D., Jaume, J.C., and McLachlan, S.M. 1998. The thyrotropin (TSH) receptor: interaction with TSH and autoantibodies. Endocr. Rev. 19:673-716.

7. Kosugi, S., and Mori, T. 1996. Cysteine-699, a possible palmitoylation site of the thyrotropin receptor, is not crucial for cAMP or phosphoinositide signaling but is necessary for full surface expression. Biochem. Biophys. Res. Commun. 221:636-640.

8. Ikuyama, S., Niller, H.H., Shimura, H., Akamizu, T., and Kohn, L.D. 1992. Characterization of the 5 -flanking region of the rat thyrotropin receptor gene. Mol. Endocrinol. 6:793-804.

9. Wilson, B., Raghupathy, E., Tonoue, T., and Tong, W. 1968. TSH-like actions of dibutyryl-cAMP on isolated bovine thyroid cells. Endocrinology. 83:877-884.

10. Field, J.B., Ealey, P.A., Marshall, N.J., and Cockcroft, S. 1987. Thyroid-stimulating hormone stimulates increases in inositol phosphates as well as cyclic AMP in the FRTL-5 rat thyroid cell line. Biochem. J. 247:519-524.

11. Riedel, C., Levy, O., and Carrasco, N. 2001. Posttranscriptional regulation of the sodium/iodide symporter by thyrotropin. J. Biol. Chem. 276:21458-21463.

12. Laugwitz, K.L., et al. 1996. The human thyrotropin receptor: a heptahelical receptor capable of stimulating members of all four $\mathrm{G}$ protein families. Proc. Natl. Acad. Sci. USA. 93:116-120.

13. Huber, G.K., Weinstein, S.P., Graves, P.N., and Davies, T.F. 1992. The positive regulation of human thyrotropin (TSH) receptor messenger ribonucleic acid by recombinant human TSH is at the intranuclear level. Endocrinology. 130:2858-2864

14. Akamizu, T., et al. 1990. Cloning, chromosomal assignment, and regulation of the rat thyrotropin receptor: expression of the gene is regulated by thyrotropin, agents that increase cAMP levels, and thyroid autoantibodies. Proc. Natl. Acad. Sci. USA. 87:5677-5681.
15. de Bernard, S., et al. 1999. Sequential cleavage and excision of a segment of the thyrotropin receptor ectodomain. J. Biol. Chem. 274:101-107.

16. Buckland, P.R., and Rees, S.B. 1984. A structural comparison of guinea pig thyroid and fat TSH receptors by photoaffinity labelling. FEBS Lett. 166:109-114.

17. Misrahi, M., and Milgrom, E. 1997. Cleavage and shedding of the TSH receptor. Eur. J. Endocrinol. 137:599-602.

18. Chazenbalk, G.D., et al. 1997. Evidence that the thyrotropin receptor ectodomain contains not one, but two, cleavage sites. Endocrinology. 138:2893-2899.

19. Couet, J., et al. 1996. Shedding of human thyrotropin receptor ectodomain. Involvement of a matrix metalloprotease. J. Biol. Chem. 271:4545-4552.

20. Graves, P.N., Vlase, H., Bobovnikova, Y., and Davies, T.F. 1996. Multimeric complex formation by the thyrotropin receptor in solubilized thyroid membranes. Endocrinology. 137:3915-3920.

21. Smith, B.R. 1972. Binding of long-acting thyroid stimulator to $4 \mathrm{~S}$ thyroid protein coupled to sepharose. J. Endocrinol. 52:229-237.

22. Chazenbalk, G.D., et al. 2002. Thyroid-stimulating autoantibodies in Graves disease preferentially recognize the free A subunit, not the thyrotropin holoreceptor. J. Clin. Invest. 110:209-217. doi:10.1172/JCI200215745.

23. Chazenbalk, G.D., Tanaka, K., McLachlan, S.M., and Rapoport, B. 1999. On the functional importance of thyrotropin receptor intramolecular cleavage. Endocrinology. 140:4516-4520.

24. Vlaeminck-Guillem,V., Ho, S.C., Rodien, P., Vassart, G., and Costagliola, S. 2002. Activation of the cAMP pathway by the TSH receptor involves switching of the ectodomain from a tethered inverse agonist to an agonist. Mol. Endocrinol. 16:736-746.

25. Szkudlinski, M.W., Fremont, V., Ronin, C., and Weintraub, B.D. 2002. Thyroid-stimulating hormone and thyroid-stimulating hormone receptor structure-function relationships. Physiol. Rev. 82:473-502.

26. Zhang, M., et al. 2000. The extracellular domain suppresses constitutive activity of the transmembrane domain of the human TSH receptor: implications for hormone-receptor interaction and antagonist design. Endocrinology. 141:3514-3517.

27. Latif, R., Graves, P., and Davies, T.F. 2001. Oligomerization of the human TSH receptor: fluorescent protein-tagged hTSHR reveals post-translational complexes. J. Biol. Chem. 276:45217-45224.

28. Latif, R., Graves, P.N., and Davies, T.F. 2002. A new action for TSH: the regulation of thyrotropin receptor oligomerization. Program. Abstr. Endocr. Soc. Annu. Meet. 83:135. (Abstr.)

29. Miura, Y., Hanada, K., and Jones, T.L. 2001. G(s) signaling is intact after disruption of lipid rafts. Biochemistry. 40:15418-15423.

30. Moffett, S., Brown, D.A., and Linder, M.E. 2000. Lipid-dependent targeting of $\mathrm{G}$ proteins into rafts. J. Biol. Chem. 275:2191-2198.

31. Adams, D.D. 1980. Thyroid-stimulating autoantibodies. Vitam. Horm. 38:119-203.

32. Chabaud, O., and Lissitzky, S. 1977. Thyrotropinspecific binding to human peripheral blood monocytes and polymorphonuclear leukocytes. Mol. Cell. Endocrinol. 7:79-87.

33. Davies, T.F., Teng, C.S., McLachlan, S.M., Smith, B.R., and Hall, R. 1978. Thyrotropin receptors in adipose tissue, retro-orbital tissue and lymphocytes. Mol. Cell. Endocrinol. 9:303-310.

34. Bagriacik, E.U., and Klein, J.R. 2000. The thyrotropin (thyroid-stimulating hormone) receptor is expressed on murine dendritic cells and on a subset of CD45RBhigh lymph node $T$ cells: functional role for thyroid-stimulating hormone during immune activation. J. Immunol. 164:6158-6165. 
35. Murakami, M., et al. 1996. Thymic hyperplasia in patients with Graves' disease. Identification of thyrotropin receptors in human thymus. J. Clin. Invest. 98:2228-2234.

36. Spitzweg, C., Joba, W., and Heufelder, A.E. 1999 Expression of thyroid-related genes in human thymus. Thyroid. 9:133-141.

37. Prummel, M.F., et al. 2000. Expression of the thyroid-stimulating hormone receptor in the folliculo-stellate cells of the human anterior pituitary. J. Clin. Endocrinol. Metab. 85:4347-4353.

38. Brokken, L.J., Scheenhart, J.W., Wiersinga, W.M. and Prummel, M.F. 2001. Suppression of serum TSH by Graves' Ig: evidence for a functional pituitary TSH receptor. J. Clin. Endocrinol. Metab. 86:4814-4817.

39. Davies, T.F., Smith, B.R., and Hall, R. 1978. Binding of thyroid stimulators to guinea pig testis and thyroid. Endocrinology. 103:6-10.

40. Kumar, R.S., et al. 2000. Cloning and functional expression of a thyrotropin receptor from the gonads of a vertebrate (bony fish): potential thyroid-independent role for thyrotropin in repro- duction. Mol Cell. Endocrinol 167:1-9.

41. Sellitti, D.F., et al. 2000. Renal expression of two 'thyroid-specific' genes: thyrotropin receptor and thyroglobulin. Exp. Nephrol. 8:235-243.

42. Crisanti, P., et al. 2001. The expression of thyrotropin receptor in the brain. Endocrinology. 142:812-822.

43. Cornelius, P., MacDougald, O.A., and Lane, M.D. 1994. Regulation of adipocyte development. Annu. Rev. Nutr. 14:99-129.

44. Haraguchi, K., Shimura, H., Lin, L., Endo, T., and Onaya, T. 1996. Differentiation of rat preadipocytes is accompanied by expression of thy rotropin receptors. Endocrinology. 137:3200-3205.

45. Endo, T., Ohta, K., Haraguchi, K., and Onaya, T. 1995. Cloning and functional expression of a thyrotropin receptor cDNA from rat fat cells. J. Biol. Chem. 270:10833-10837.

46. Roselli-Rehfuss, L., Robbins, L.S., and Cone, R.D. 1992. Thyrotropin receptor messenger ribonucleic acid is expressed in most brown and white adipose tissues in the guinea pig. Endocrinology. 130:1857-1861.
47. Bahn, R.S., et al. 1998. Thyrotropin receptor expression in Graves' orbital adipose/connective tissues: potential autoantigen in Graves' ophthalmopathy. J. Clin. Endocrinol. Metab. 83:998-1002.

48. Valyasevi, R.W., et al. 1999. Differentiation of human orbital preadipocyte fibroblasts induces expression of functional thyrotropin receptor J. Clin. Endocrinol. Metab. 84:2557-2562.

49. Drvota, V., et al. 1995. Evidence for the presence of functional thyrotropin receptor in cardiac muscle. Biochem. Biophys. Res. Commun. 211:426-431.

50. Sellitti, D.F., et al. 1997. Differential expression of thyrotropin receptor mRNA in the porcine heart Thyroid. 7:641-646.

51. Inoue, M., Tawata, M., Yokomori, N., Endo, T. and Onaya, T. 1998. Expression of thyrotropin receptor on clonal osteoblast-like rat osteosarcoma cells. Thyroid. 8:1059-1064.

52. Marians, R.C., et al. 2001. TSH serves as a negative regulator of osteoblast and osteoclast development and function as demonstrated in the TSH receptor knock-out mouse. American Thyroid Association 2001 Abstract Guide. 2:37. (Abstr.) 